\title{
Laser Microprobe Mass Spectrometry of Quaternary Phosphonium Salts: Direct Versus Matrix-Assisted Laser Desorption
}

\author{
Jan Claereboudt and Magda Claeys \\ Department of Pharmaceutical Sciences, University of Antwerp, Antwerp, Belgium
}

Herman Geise and Renaat Gijbels

Department of Chemistry, University of Antwerp, Antwerp, Belgium

\author{
Akos Vertes \\ The George Washinglon Universily, Departmenl of Clemistry, Washington DC, USA
}

The use of laser microprobe mass spectrometry (LMMS) for the structural characterization of thermolabile quaternary phosphonium salts has been evaluated. A comparison has been made between LM mass spectra obtained by direct analysis of "neat" organic salts and the corresponding "matrix-assisled" LM mass spectra. Main limitations of LMMS for the direct analysis of neat organic salts (i.e., no matrix) result from (1) formation of artifact ions that originate from thermal degradation and surface recombination reactions and (2) poor shotto-shot reproducibility of the spectra. Dilution of the organic salts in a suitable, UV-absorbing matrix (e.g., nicotinic acid) significantly enhances the quality of the LM mass spectra. Improvements are: (1) an increase of the ion yield of preformed cations, (2) reduction or elimination of thermal decomposition and other deleterious surface reactions, and (3) a much better shot-to-shot spectral reproducibility. An interesting analytical feature is that these LM mass spectra, which contain only a few matrix peaks, can be obtained for subnanogram amounts of sample.

The results also show that triphenylphosphonium salts with polycyclic aromatic substituents can be used as "molecular thermometers" to probe both the temperatures experienced by the sample molecules during the laser-induced desorption ionization process and the internal energies of the desorbed ion species. In this way, quaternary phosphonium salts can be used for evaluating whether improvements have been achieved by applying different sample treatments. Comparison of four different matrices (i.e., nicotinic acid, ammonium chloride, glycerol, and 3-nitrobenzylalcohol) indicates that the effectiveness of a matrix to reduce thermal degradation and to decrease the internal energies of the ions depends on the UV-absorption characteristics and the volatilization/sublimation temperature of the matrix material. (J Am Soc Mass Spectrom 1993, 4, 798-812)

$\mathrm{T}$ The use of laser ionization techniques for the analysis of nonvolatile and thermolabile compounds in organic and biological mass spectrometry becomes more and more established. As with several other desorption ionization techniques [e.g. field desorption mass spectrometry (FDMS), molecular secondary ion mass spectrometry (SIMS), and fast atom bombardment mass spectrometry (FABMS)], laserinduced ionization enables us to obtain (quasi)molecular ion signals of high relative intensity from compounds that are too involatile or labile to give molecular ion signals of appreciable intensity in con-

Address reprint requests to Magda Claeys, Department of Pharmaceutical Sciences, University of Antwerp, Universiteitsplein 1, B-2610 Wilrijk-Antwerp, Belgium. ventional electron impact (EI) and/or chemical ionization (CI) mass spectrometry. Quaternary phosphonium salts form a class of intractable thermolabile compounds that readily undergo thermal decomposition prior to volatilization and ionization in the gas phase. Analysis of these fragile organic salts, therefore, represents an ultimate test case for evaluating the performance of various desorption ionization (DI) techniques, such as laser microprobe mass spectrometry (LMMS).

This study discusses the positive ion LM mass spectra of a series of monophosphonium and bisphosphonium halides, previously analyzed by FABMS [1]. Special interest is focused on the comparison of the LM mass spectra obtained by direct analysis of the "neat" organic salts with the corresponding "matrix-assisted" 
LM mass spectra. To recognize ions that may arise from thermal degradation of the organic salts, comparisons are also made with direct probe EI mass spectra. Specific objectives of this study are: (1) to evaluate the potential of LMMS for obtaining mass spectra of phosphonium salts, (2) to investigate the occurrence of thermal degradation and other deleterious surface reactions induced by laser irradiation of organic solids, (3) to explore the effects of diluting the sample in both solid and liquid (UV-absorbing) matrices, and (4) to discuss mechanistic implications.

\section{Experimental}

\section{Instrumentation}

All LMMS experiments were performed with a standard LAMMA-500 laser microprobe time-of-flight mass spectrometer equipped with a $Q$-switched frequency quadrupled Nd-YAG laser ( $\lambda-266 \mathrm{~nm}$, pulse length $=15 \mathrm{~ns}$ ). The laser beam was focused by a microscope objective to a minimum spot size of $1 \mu \mathrm{m}$ in diameter, or slightly defocused to spot sizes up to $10 \mu \mathrm{m}$. The laser intensity could be varied by an amplifier and by a UV-absorbing filter system. Unless otherwise reported, LM mass spectra were obtained in the so-called laser desorption mode (i.e., the laser irradiance was kept within a range of about one to five times the threshold level at which sample-specific ions start to appear). This threshold irradiance was determined by a series of shots prior to the actual measurement for every compound and type of sample preparation. A complete mass spectrum could be recorded for each laser shot, although signal averaging was used to improve the spectra. To reduce fluctuations in relative ion abundances under single-shot conditions, 15 laser shots were usually averaged for each reported LM mass spectrum. One of the major disadvantages of the LAMMA-500 instrumentation is its low mass resolution $(\mathrm{M} / \Delta \mathrm{M}=600)$, which does not allow unambiguous determination of the exact elemental composition of the detected ions. Consequently, proposed structural assignments and fragmentation patterns should be regarded as tentative. Interpretation was based on comparison of LMMS results for structurally related salts having different substituents. Furthermore, as the same precursor ions were observed in LMMS, FABMS, and/or EIMS, fragmentation patterns in LMMS are suggested on the basis of FAB tandem mass spectrometry (MS/MS) and EI MS/MS data [1].

Direct probe EI mass spectra were obtained with the VG 70-SEQ hybrid mass spectrometer equipped with a standard $\mathrm{EI} / \mathrm{CI}$ ion source. The source was operated at a temperature of $220^{\circ} \mathrm{C}$, with a trap current of $200 \mu \mathrm{A}$ and an electron energy of $70 \mathrm{eV}$. The samples were introduced via the direct inlet probe, which was programmed from $100{ }^{\circ} \mathrm{C}$ to $300{ }^{\circ} \mathrm{C}$ at a rate of $50{ }^{\circ} \mathrm{C}$ $\min ^{-1}$.

\section{Materials}

The phosphonium salts were either obtained commercially or synthesized by standard methods [2]. The structures of the compounds investigated in this study are given in Tables 1 and 2. The matrices nicotinic acid (NicAc), ammonium chloride $\left(\mathrm{NH}_{4} \mathrm{Cl}\right)$, glycerol, and 3-nitrobenzylalcohol (3-NBA) were purchased from Janssen Chimica (Geel, Belgium).

\section{Sample Preparation}

For LMMS analysis of "neat" phosphonium salts (i.e., no matrix) samples were prepared from ground powders and deposited on a formvar-coated electron microscopy (EM) grid. The micromorphology of the solid samples appeared to have a strong influence on the mass spectral results, both qualitatively (degree of fragmentation) and quantitatively (peak intensities). In our experience, the most reproducible results were usually obtained from very fine particles with diameters of about 1-2 $\mu \mathrm{m}$ (i.e., comparable to the diameter of the pilot laser spot).

Table 1. Structures of the monophosphonium salts (1-26) studied.

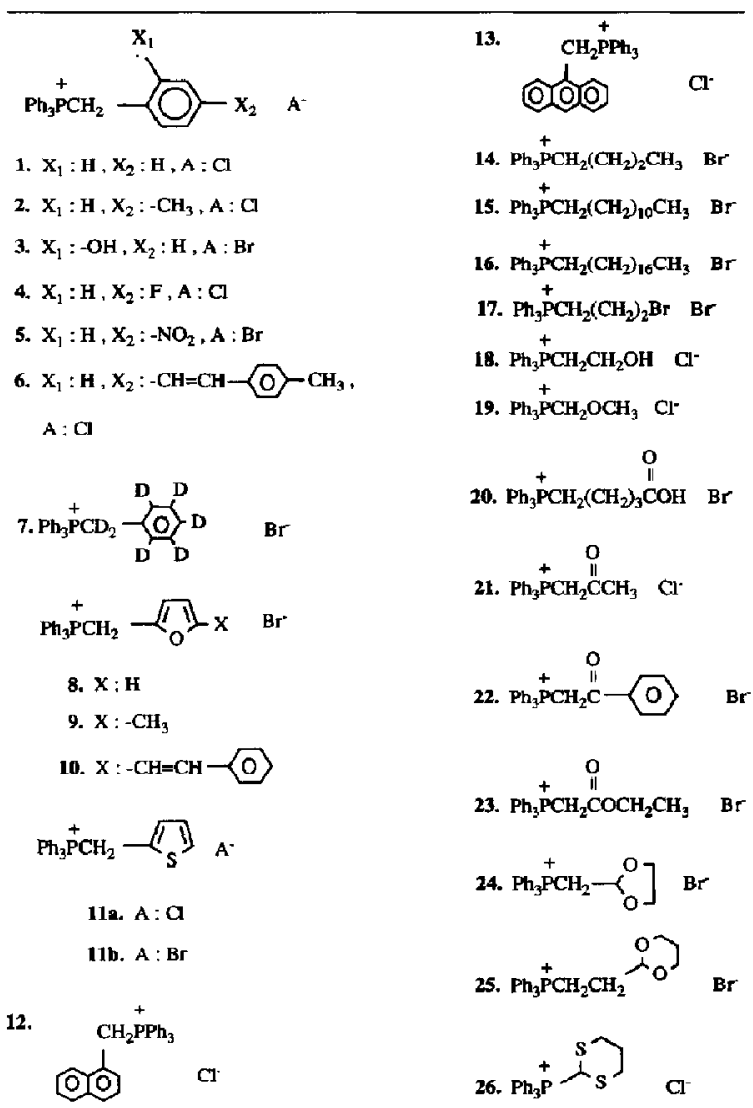


Table 2. Structures of the bisphosphonium salts (27-40) studied.

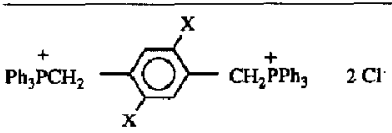

27. $\mathrm{X}: \mathrm{H}$

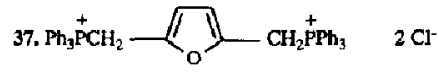

28. $\mathrm{X}:-\mathrm{CH}_{3}$

29. $\mathrm{X}:-\mathrm{OCH}_{3}$

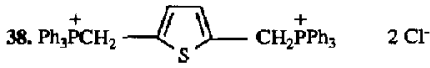

31. $X:-O-p r o p y 1$

31. $\mathrm{X}$ : - $\mathrm{O}$-isobutyl

32. $\mathrm{X}$ : -O-pentyl

33. $\mathrm{X}$ : - O-isopenty]

34. $\mathrm{X}$ : -O-hexyl

35. $\mathrm{X}$ : - O-heptyI

36. $\mathrm{X}:-\mathrm{O}-$-octyl

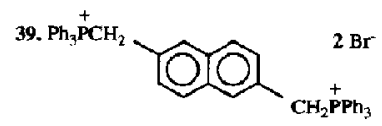

40.

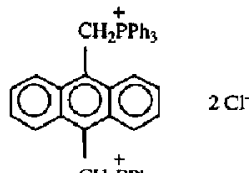

For matrix-assisted LMMS experiments with the liquid matrices glycerol and 3-NBA, a 1-3 $\mu \mathrm{L}$ droplet of matrix solution, containing approximately $40 \mathrm{ng}$ of phosphonium salt, was deposited on a formvar-coated EM grid. Practical disadvantages of the use of these liquid matrices were due to (1) the high vapor pressure of the matrices and (2) the transmission-type sample stage of the LAMMA-500, which makes it very difficult to analyze liquid droplets with inhomogeneous thickness.

Sample preparation for matrix-assisted LMMS experiments with the solid matrices $\mathrm{NicAc}$ and $\mathrm{NH}_{4} \mathrm{Cl}$ was based on the procedure we used to prepare peptide samples for transmission geometry measurements [3]. A $10^{-4} \mathrm{M}$ solution of phosphonium salt, prepared in bidistilled water or reagent-grade Methanol, was mixed with a $10^{-2} \mathrm{M}$ aqueous solution of NicAc $\left(\mathrm{NH}_{4} \mathrm{Cl}\right)$ in a $1: 1$ ratio. About $2 \mu \mathrm{L}$ of this mixture was applied onlo a formvar-coated EM grid. The sample was then dried by hot air of approximately $40^{\circ} \mathrm{C}$. Evaporation of the solvent produced optically homogeneous, thin crystals covering an area of about 3 mum $^{2}$, surrounded by a thicker rim. Generally, LM mass spectra could be obtained from the whole sample area, but the spectra with highest signals were usually produced from the rim. The best spectra were produced when hitting the side of thin enough crystals to perforate the particle in one shot. Parts of these platelets were completely evaporated in the interaction, producing ample ions. Thicker crystallites or the center part of the particles produced weaker signals or no spectra at all. For all these experiments, it turned out to be advantageous that the LAMMA system allows for simultaneous observation of the irradiated area through an optical microscope (magnification $400 \times$ ). In this way, success or failure of desorption could be corre lated to the microscopic state of the sample (i.e., homo- geneity of the mixture, partial or total separation of the components, or recrystallization).

\section{Results and Discussion}

\section{Direct LMMS Analysis of "Neat" Phosphonium Salts}

Monophosphonium salts $(1-26)$. In the case of phosphonium salts, practically all organic information is available from the positive ion spectra. The only feature of interest in the negative ion LM mass spectra is the halide anion, which is used to determine the anionic mass. The positive ion LM mass spectrum of benzyltriphenylphosphonium chloride (1) analyzed in neat form (i.e., no matrix) and obtained at threshold laser irradiance is shown in Figure 1a. The base peak in the spectrum at $m / z 353$ corresponds to the intact cation, $\mathrm{C}^{+}$. The formation of this ion is rationalized by direct desorption of the preformed cation from the solid state (Scheme I). Characteristic fragment ions of the intact cation are detected at $m / z 262$ and $m / z$ 91, corresponding to the triphenylphosphine ion $\left[\mathrm{PPh}_{3}\right]^{+*}$ and the benzyl ion $\left[\mathrm{PhCH}_{2}\right]^{+}$, respectively. The odd-electron triphenylphosphine ion most probably serves as the precursor for the fragment ions at $m / z 261\left[\mathrm{Ph}_{3} \mathrm{P}\right.$ $-\mathrm{H}]^{+}, m / z 185\left[\mathrm{Ph}_{2} \mathrm{P}\right]^{+}, m / z 183\left[\mathrm{Ph}_{2} \mathrm{P}-\mathrm{H}_{2}\right]^{+}$, $m / z 108[\mathrm{PhP}]^{+}$, and $m / z 107[\mathrm{PhP}-\mathrm{H}]^{+}$(Scheme I). A similar mass spectral behavior was found when a different DI method (i.e., FABMS) was applied, and the fragmentation pathways were supported by performing FAB MS/MS [1].

In comparison with the FAB mass spectrum, the LM mass spectrum shows a higher relative abundance for the $[C-1]^{+}$and $[C-2]^{+}$ions at $m / z \quad 352$ and 351 . Absence of these ions in the product ion spectrum of the intact cation obtained by FAB MS/MS suggests that they originate from reactions occurring at the surface prior to desorption, rather than from a gasphase fragmentation process. Comparison of the LM mass spectrum (Figure 1a) with the corrosponding direct probe EI mass spectrum of benzyltriphenylphosphonium chloride (Figure 2) indicates that the ions at $m / z 352$ and 351 result from thermal degradation of the salt. As expected, the intact cation is not observed in the EI mass spectrum. EI requires volatilization of the neutral salt (PhCII ${ }_{2} \mathrm{PPh}_{3} \mathrm{Cl}$ ), which generally results in thermal decomposition according to the following pathways [2]:

$$
\begin{gathered}
{\left[\mathrm{PhCH}_{2} \mathrm{PPh}_{3}\right]^{+} \mathrm{Cl}_{(s o l d d)}^{-} \stackrel{\Delta \mathrm{T}}{\longrightarrow} \mathrm{PhCH}=\mathrm{PPh}_{3_{(\mathrm{g})}}+\mathrm{HCl}_{(\mathrm{g})}} \\
{\left[\mathrm{PhCH}_{2} \mathrm{PPh}_{3}\right]^{+} \mathrm{Cl}_{(\mathrm{solid})}^{-} \stackrel{\Delta \mathrm{T}}{\longrightarrow} \mathrm{PhCH}_{2} \mathrm{Cl}_{(\mathrm{g})}+\mathrm{PPh}_{3_{(\mathrm{g})}}}
\end{gathered}
$$

Electron ionization of the more volatile degradation products and subsequent fragmentation of their molec- 

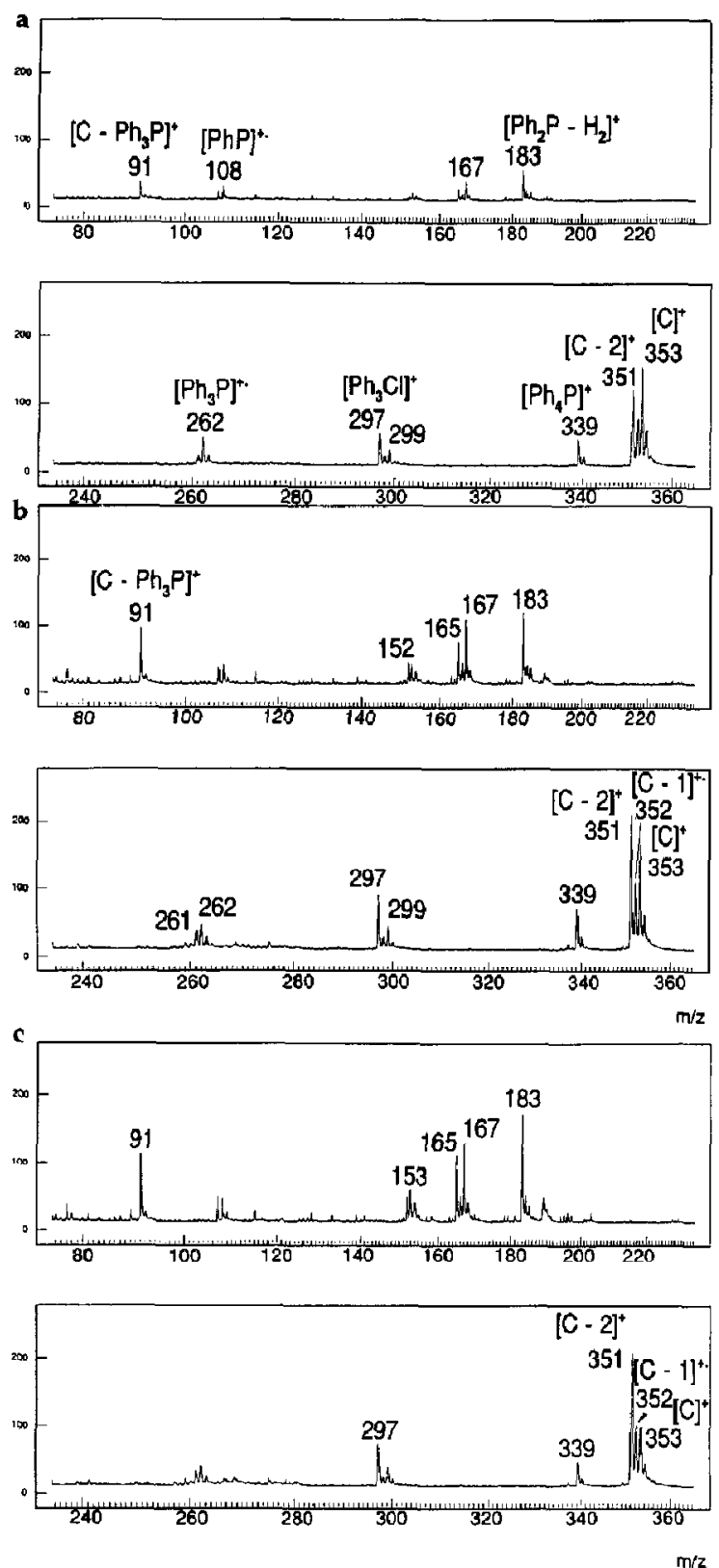

Figure 1. Positive ion LM mass spectra of neat benzyltriphenylphosphonium chloride (1) at increasing laser irradiance: (a) threshold irradiance, $\mathrm{E}_{\mathrm{o}}$; (b) $3 \times \mathrm{E}_{\mathrm{o}}$; (c) $10 \times \mathrm{E}_{0}$. The peak intensities are given in arbitrary units.

ular ions gives rise to the ions detected in the EI mass spectrum (Figure 2). The term "electron ionization" refers to the generation of odd-electron molecular $\left(\mathrm{M}^{+\cdot}\right)$ ions. Electron ionization of the degradation products may result from photoionization or collisional ionization processes that take place during laser irradiation. The molecular ion $\left(\mathrm{M}^{+}\right)$of phenylmethylenetri-

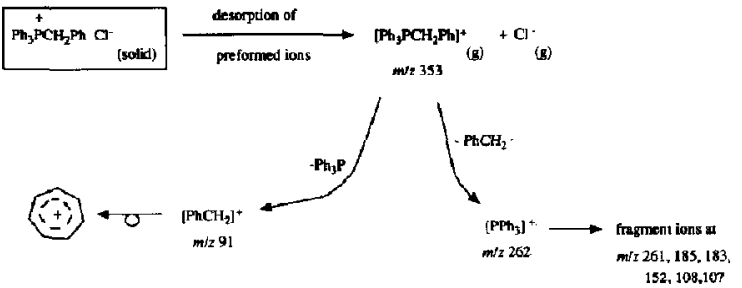

Scheme I

phenylphosphorane, which is the major thermal decomposition product of benzyltriphenylphosphonitum chloride, is observed at $m / z 352$ (i.e., $\left[\mathrm{PhCH}=\mathrm{PPh}_{3}\right]^{+}$. or $\left.[C-1]^{+}\right)$. This ylid ion is formed by thermal elimination of $\mathrm{HCl}$ from the salt molecule (according to eq 1) and subsequent electron innization of the neutral degradation product.

The presence of the ion at $m / z 352$ in the LM mass spectrum (Figure 1a) suggests that a similar degradation process takes place during laser desorption of neat benzyltriphenylphosphonium chloride. This idea is supported by the detection of two characteristic fragment ions of the ylid ion at $m / z 351$ and $m / z 167$. These ions result from expulsion of a hydrogen radical and a $\mathrm{Ph}_{2} \mathrm{P}^{\prime}$ radical, respectively, from the oddelectron $\left[\mathrm{PhCH}=\mathrm{PPh}_{3}\right]^{+\cdot}$ ion (Scheme II). A similar fragmentation behavior is observed in the EI mass spectrum (Figure 2). The fragmentation pathways that yield the bridged $[\mathrm{C}-2]^{+}$ion at $\mathrm{m} / z \quad 351$ and the diphenylmethyl cation at $\mathrm{m} / \mathrm{z} 167$ were supported by recording the EI MS/MS product ion spectrum of the ylid ion at $m / z 352$ (not shown).

The presence of ions at $m / z 352,351$, and 167 in the LM mass spectrum and the EI mass spectrum indicates that thermal degradation of the salt, with subsequent electron ionization and fragmentation of the degradation products, also occurs during laser desorption of neat organic salts.

Molecular ions of the degradation products that are formed by the alternative thermal decomposition process (eq 2) are less abundant in the LM mass spectrum. Only the $\left[\mathrm{PPh}_{3}\right]^{+\cdot}$ ion at $m / z 262$ is detected. However, this ion may also originate from unimolecular

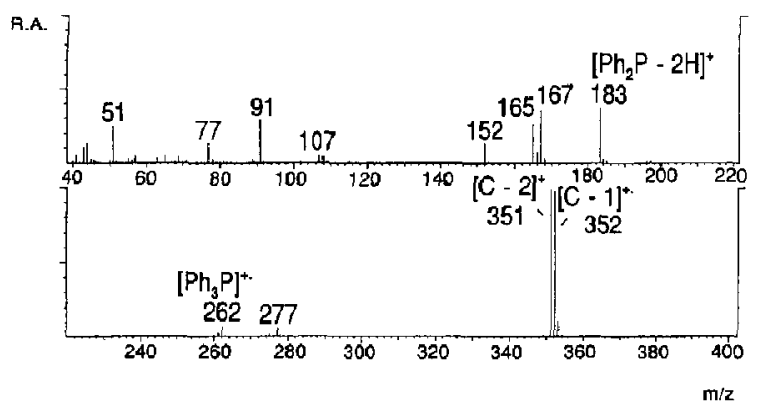

Figure 2. Direct probe EI mass spectrum of benzyltriphenylphosphonium chloride (1). 


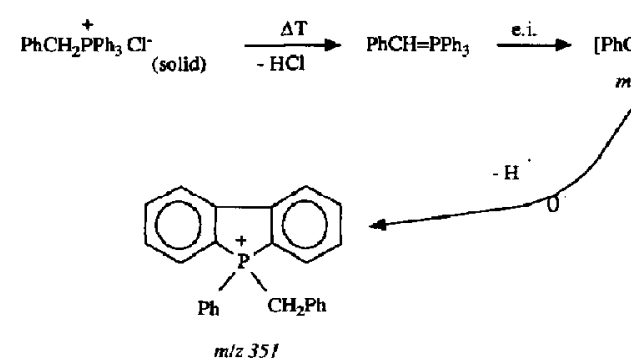

( $\Delta \mathrm{T}=$ thermal degradation, e.i. $=$ electron ionization $)$

Scheme II

decomposition of the intact cation (i.e., homolytic cleavage of the bond between the phosphorus and the benzyl substituent [see above]).

Other ions of interest in the LM mass spectrum are detected at $m / z 297 / 299$, and 339 (Figure 1a). The 3:1 intensity ratio of the peaks at $m / z 297$ and 299 is consistent with the presence of one chlorine atom (i.e., $\left.\left[\mathrm{Ph}_{3} \mathrm{PCl}\right]^{+}\right)$. The ion at $\mathrm{m} / z 339$ corresponds to the tetraphenylphosphonium cation, $\left[\mathrm{Ph}_{4} \mathrm{P}\right]^{+}$. Both ions, which are absent in the corresponding EI mass and FAB mass spectra, point to surface recombination reactions on the laser-irradiated surface. A possible ion formation mechanism, which involves the interaction between radical ion species (corresponding to electron-ionized thermal degradation products) and free radicals in the laser-generated plume, is given in Scheme JII. The appearance of two additional low-abundance recombination ions (i.e., the $\left[\mathrm{PhCH}(\mathrm{Cl}) \mathrm{PPh}_{3}\right]^{+}$ion at $m / z \quad 387$ and 389 and the $\left[\mathrm{PhCH}(\mathrm{Ph}) \mathrm{PPh}_{3}\right]^{+}$ion at $m / z 429$, can also be explained by this mechanism. Similar recombination ions have been previously reported for the FD mass spectrum of benzyltriphenylphosphonium chloride [4].

In conclusion, these results show that the ion current formed during LMMS of neat benzyltriphenylphosphonium chloride consists of three contributions: (1) desorption of the preformed cation and formation of its characteristic fragment ions (Scheme I); (2) thermal degradation of the salt with subsequent electron ionization and fragmentation of the degradation products (Scheme $\Pi$ ), and (3) surface recombination reactions (Scheme III). The simultaneous ofcurrence of the various ionization processes can be explained by the fact that laser impact creates an energy gradient along the sample surface and starls an entire series of processes, ranging from complete disintegration in the central area to pyrolysis and thermal degraclation and to gradually softer conditions enabling intact desorption of preformed ions in the periphery. Variations of the laser power density will change the relative contributions of the various processes. Valuable structural information is only derived from the intact cation and its diagnostic fragment ions, enabling determination of the cationic mass and char-
$\left[\mathrm{Ph}_{3} \mathrm{P}\right]^{+\cdot}+\mathrm{Cl}$

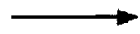
$\left[\mathrm{Ph}_{3} \mathrm{PCl}\right]^{+}$.
$m / 2262$
$m / 2297 / 299$
$(3: 1)$
$\begin{array}{ll}{\left[\mathrm{Ph}_{3} \mathrm{P}\right]^{+-}+\mathrm{Ph} \cdot} & \longrightarrow \\ m / z 262 & {\left[\mathrm{Ph}_{4} \mathrm{P}\right]^{+}} \\ & m / z 339\end{array}$
$\left[\mathrm{PhCH}=\mathrm{PPh}_{3}\right]^{+}+\mathrm{Cl} \longrightarrow\left[\mathrm{PhCH}(\mathrm{Cl}) \mathrm{PPh}_{3}\right]^{+}$

$m / 2352$

$m / z 387 / 389(3: 1)$
$\left[\mathrm{PhCH}=\mathrm{PPh}_{3}\right]^{+\cdot}+\mathbf{P h} \cdot$

$m / z 352$

Scheme III
$\left[\mathrm{PhCH}(\mathrm{Ph}) \mathrm{PPh}_{3}\right]^{\prime}$

$m / 2429$ acterization of the structural subgroups. Figure 1 shows that the relative abundance of the intact cations in the LM mass spectrum is a function of the applied laser power density. At threshold laser irradiance, the intact cations $(\mathrm{m} / \mathrm{z}$ 353) form the base peak in the spectrum (Figure 1a). The relative abundance of the intact cations, however, decreases with increasing laser power density (Figure $1 \mathrm{~b}$ and $\mathrm{c}$ ), as a result of the higher degree of fragmentation of intact cations and increased contributions of competing processes (i.e., thermal degradation and/or surface recombination reactions). The ions originating from these competing ionization processes (i.e., $m / z$. 352, 351, 339, and 297) cannot be directly correlated with the molecular structure of the organic salt and, consequently, complicate the interpretation of the LM mass spectrum. These ions are only indicative of the pyrolytic surface reactions induced by laser impact. Figure 1 shows that the relative abundances of these ions increase with increasing laser irradiance.

The mass spectral characteristics discussed for benzyltriphenylphosphonium chloride (1) are representative for the LM mass spectra of the other triphenylphosphonium salts with a $-\mathrm{CH}_{2}$ aryl substituent (i.e., general formula $\left[\mathrm{ArCH}_{2} \mathrm{PPh}_{3}\right]^{+} \mathrm{A}^{-}$, where $\mathrm{Ar}=$ aryl and $\mathrm{A}=$ halide anion) (2-13). Diagnostic ions in the spectra correspond to the intact cation $\left[\mathrm{ArCH}_{2} \mathrm{PPh}_{3}\right]^{+}$(i.e., $\mathrm{C}^{+}$) and its characteristic fragment ions $\left[\mathrm{ArCH}_{2}\right]^{+}$and $\left[\mathrm{PPh}_{3}\right]^{+*}$, and fragment ions of the $\left[\mathrm{PPh}_{3}\right]^{+\cdot}$ ion at $m / z 261,185,183,152,108$, and 107. Other ions formed are the result of thermal degradation, that is, $\left[\mathrm{ArCH}=\mathrm{PPh}_{3}\right]^{+\cdot}$ (i.e., $[\mathrm{C}-1]^{+\cdot}$ ), $\left[\mathrm{ArCH}=\mathrm{PPh}_{3}-\mathrm{H}\right]^{+}$(i.e., $[\mathrm{C}-2]^{+}$) and $[\mathrm{ArCHPh}]^{+}$ or result from surface recombination reactions, that is, $\left[\mathrm{Ph}_{4} \mathrm{P}\right]^{+},\left[\mathrm{Ph}_{3} \mathrm{PA}\right]^{+}$, and $\left[\mathrm{ArCH}(\mathrm{A}) \mathrm{PPh}_{3}\right]^{+}$.

A comparison between the LM mass spectra of benzyl- (1), 4-methylbenzyl- (2), and 4-(4'-methylstyryl)benzyl-(6) triphenylphosphonium chloride shows that the relative contributions of the intactly released cation $\mathrm{C}^{+}$, the ionized thermal degradation product $[\mathrm{C}-1]^{+}$, and its major fragment ion $[\mathrm{C}-2]^{+}$ 
are a function of the desorption characteristics of the compound studied (Figure 3). Benzyltriphenylphosphonium chloride (1), the salt with the lowest relative molecular mass $\left(\mathrm{M}_{\mathrm{r}}\right)$, desorbs at very low laser irradiance and yields relatively more preformed ions. The higher $M_{r}$ derivatives ( 2 and 6 ) require a higher threshold irradiance to desorb. Consequently, they are prone to more pronounced decomposition, giving rise to more abundant $[\mathrm{C}-1]^{+}$and $[\mathrm{C}-2]^{+}$ions. For 4-(4'-methylstyryl)benzyltriphenyl phosphonium chloride (6), the intact cation signal intensity is negligible (Figure 3c), indicating the limitations of laser desorption for the structural characterization of neat phosphonium salts. The $[\mathrm{C}-2]^{+}$ion is much more abundant than the $\mathrm{C}^{+}$ion and may lead to a wrong assignment of the cationic mass of the salt.

The monophosphonium salts with polycyclic aromatic substituents (12-13) form an interesting group of compounds because their LM mass spectra clearly demonstrate the process of thermal degradation with subsequent electron ionization. This is illustrated by the positive ion LM mass spectrum of (9-anthryl)methyltriphenylphosphonium chloride (13) (Figure 4). The molecular ion region contains three major peaks of which the one at $m / z 452$ corresponds to the radical molecular ion of the thermal decomposition product (i.e., the $\left[\mathrm{ArCH}=\mathrm{PPh}_{3}\right]^{+\cdot}$ or $[\mathrm{C}-1]^{+*}$ ion). The high relative abundance of this odd-electron ion, compared with the abundances of the $[C-1]^{+\cdot}$ ions observed for the other monophosphonium salts (1-11, 14-26), is probably due to the aromatic structure of the aryl substituent, which increases its stability. The major fragment ion of the radical ylid ion corresponds to the $[C-2]^{+}$ion at $m / z$ 451. The peak at $m / z 453$ is higher than the ${ }^{13} \mathrm{C}$ isotopic contribution of the signal at $m / z 452$ and hence includes a major contribution from intact preformed cations. The base peak at $\mathrm{m} / \mathrm{z}$ 191 corresponds to the 9-anthrylmethyl substituent (i.e., $\left[\mathrm{ArCH}_{2}\right]^{+}$), which is the major fragment ion of the intact cation. The other ions in the L.M mass spectrum

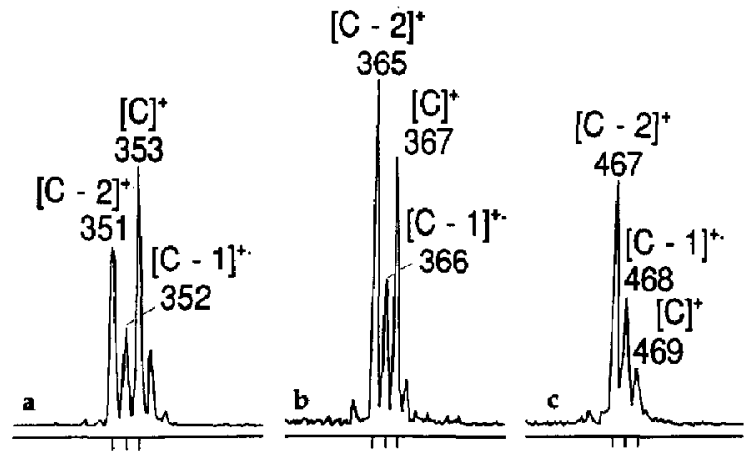

Figure 3. Positive ion LM mass spectra (intact cation mass-tocharge ratio region) of (a) benzyl-(1) (b) 4-methylbenzyl- (2), and (c) 4-(4'-methylstyryl)benzyl-triphenylphosphonium chloride (6), illustrating the competition between intact desorption and thermal decomposition.

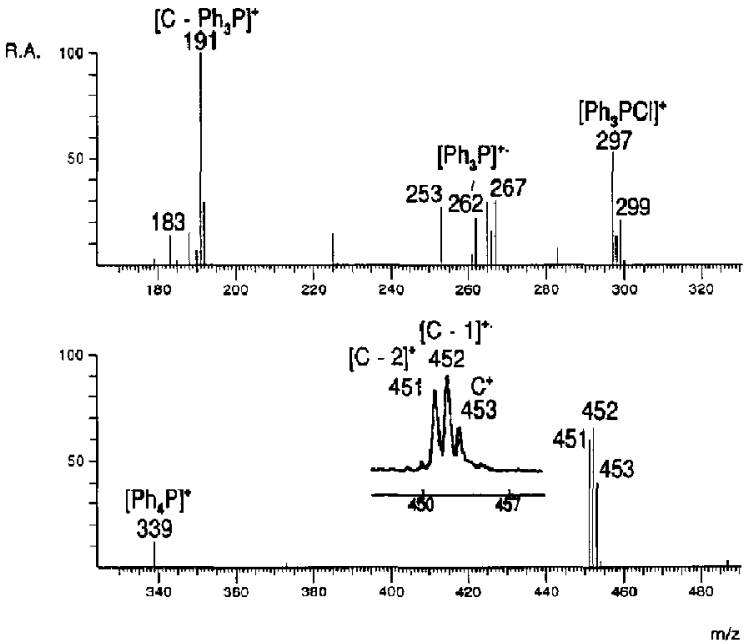

Figure 4. Positive ion LM mass spectrum of (9-anthryl)methyltriphenylphosphonium chloride (13).

can he attributed to $\left[\mathrm{Ph}_{4} \mathrm{P}\right]^{+}\left(\mathrm{m} / z\right.$ 339), $\left[\mathrm{Ph}_{3} \mathrm{PCl}\right]^{+}$ $(m / z 297 / 299),\left[\mathrm{Ph}_{3} \mathrm{P}\right]^{+\cdot}(m / z 262)$, and $\left[\mathrm{Ph}_{2} \mathbf{P}-\right.$ $\left.\mathrm{H}_{2}\right]^{+}(m / z 183)$.

A similar mass spectral behavior is observed for 1-naphthylmethyltriphenylphosphonium chloride (12), a salt that later in this study will be used as a test compound to investigate the effects of a matrix for LMMS. In addition to the intact cation $(m / z$ 403), the molecular ion region of the spectrum contains intense peaks at $\mathrm{m} / \mathrm{z} 402$ and 401 , corresponding to [C -1$]^{+\cdot}$ and $[\mathrm{C}-2]^{+}$ions, respectively (see Figure $8 \mathrm{a}$, later). The high abundance of the latter ions is proof of the occurrence of thermal degradation and subsequent electron ionization. This feature becomes less prominent in the LM mass spectra of the monophosphonium salts, which contain an alkyl substituent instead of an aryl substituent (i.e., salts 14-26). This is illustrated in the LM mass spectrum of $n$-dodecyltriphenylphosphonium bromide (15) (Figure 5). The base peak at $m / z \quad 431$ is due to the intact cation (i.e., $\left[\mathrm{Ph}_{3} \mathrm{PC}_{12} \mathrm{H}_{25}\right]^{+}$). Subsequent fragmentation of this preformed cation leads to diagnostic fragment ions at $m / z 289\left[\mathrm{Ph}_{3} \mathrm{PCH}=\mathrm{CH}_{2}\right]^{+}, m / z 263\left[\mathrm{Ph}_{3} \mathrm{PH}\right]^{+}, m / z$ $262\left[\mathrm{Ph}_{3} \mathrm{P}\right]^{+}, m / z 261\left[\mathrm{Ph}_{3} \mathrm{P}-\mathrm{H}\right]^{+}, m / z 199\left[\mathrm{Ph}_{2} \mathrm{P}=\right.$ $\left.\mathrm{CH}_{2}\right]^{+}, m / z 183\left[\mathrm{Ph}_{2} \mathrm{~L}^{3}-\mathrm{H}_{2}\right]^{+}$, and $m / z$ 108 $[\mathrm{HhP}]^{+}$. A similar fragmentation pattern was reported for the corresponding FAB mass spectrum and confirmed by obtaining the product ion tandem mass spectrum of the intact cation. Differences with the LM mass spectra of the aryltriphenylphosphonium salts are (1) the $a b$ sence of a $\left[\mathrm{C}-\mathrm{PPh}_{3}\right]^{+}$fragment ion which corresponds to the alkyl substituent bonded to the triphenylphosphine group and (2) a very low abundance of the $[C-1]^{+\cdot}(m / z 430)$ and $[C-2]^{+}(m / z 429)$ ions, indicating a smaller contribution of thermal degradation and electron ionization to the ion formation process. The abundant $\mathrm{C}^{+}$ion in the molecular 

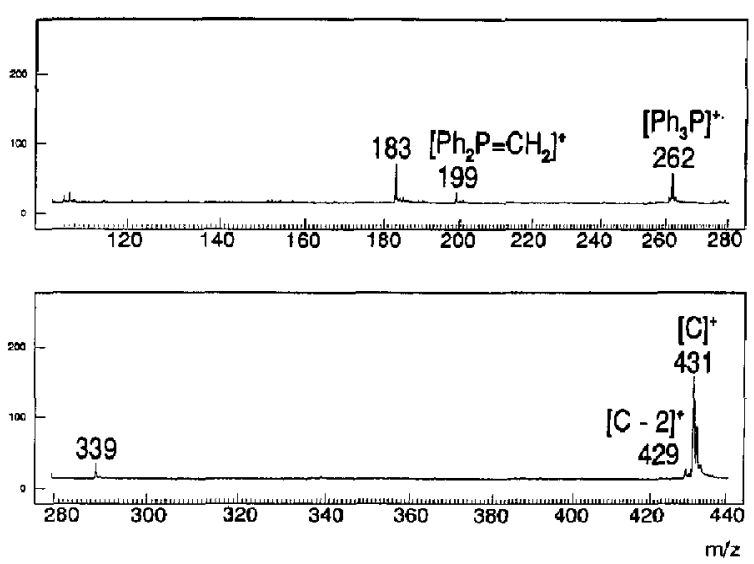

Figure 5. Positive ion LM mass spectrum of n-dodecyltriphenylphosphonium bromide (15). The peak intensities are given in arbitrary units.

ion region eliminates ambiguity in the determination of the cationic mass.

In addition to the spectral characteristics discussed above, the LM mass spectra of the "substituted" alkyltriphenylphosphonium salts (17-26) also contain diagnostic fragment ions that are related to the functional group substitution. Most of these fragment ions are formed by loss of small neutral molecules from the intact cation. This is illustrated by the LM mass spectrum of carbethoxymethyltriphenylphosphonium bromide (23) (Figure 6). The base peak at $\mathrm{m} / \mathrm{z} 349$ corresponds to the intact cation $\left(C^{+}\right)$. Substituent specific fragment ions from the intact cation are detected at $m / z 321$ (loss of $\mathrm{C}_{2} \mathrm{H}_{4}$ ), m/z 303 (loss of $\mathrm{HOC}_{2} \mathrm{H}_{5}$ ), $m / z 277$ (combined expulsion of $\mathrm{C}_{2} \mathrm{H}_{4}$ and $\mathrm{CO}_{2}$ ), $\mathrm{m} / z$ 275 (loss of $\mathrm{HCO}_{2} \mathrm{C}_{2} \mathrm{H}_{5}$ ), and $m / z 262$ (loss of a $\mathrm{C}_{2} \mathrm{H}_{5} \mathrm{O}_{2} \mathrm{CCH}_{2}$ radical). Also for the other substituted alkyltriphenylphosphonium salts (17-22, 24-26), the LMMS data provide information on the cationic mass and the functional groups.

Bisphosphonium salts (27-40). In the case of multiply charged compounds, unless other processes occur such as electron capture or fragmentation of the mulecular ion, knowledge about molecular mass requires detection of multiply charged ions. Doubly charged cations of organic bisphosphonium salts were observed in FDMS [4, 5] and FABMS [1, 6, 7]. Although no detailed investigation was reported for LMMS, the difficulty of detecting doubly charged lons in LM mass spectra of

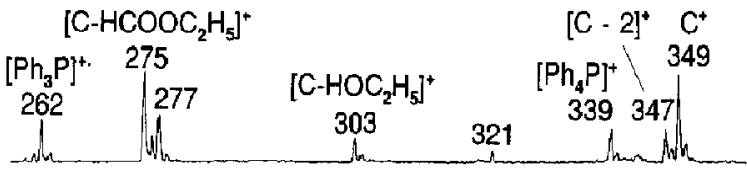

Figure 6. Positive ion LM mass spectrum of carbethoxymethyltriphenylphosphonium bromide (23). The peak intensities are given in arbitrary units. salts containing organic dications or dianions was noted [8-10].

None of the diquaternary phosphonium salts analyzed in this study (27-40) show emission of doubly charged cations. Laser desorption of the bisphosphonium salts generally results in emission of singly charged species. Due to the additional lattice forces, the threshold irradiance for the bisphosphonium salts (e.g., salt 27) is generally a factor 10 to 20 higher than for the corresponding monophosphonium salts (e.g., salt 1). These conditions consequently lead to (1) more extensive fragmentation of ions in the molecular ion region and (2) a higher amount of irradiation damage (i.e., thermal degradation and surface recombination reactions). This is shown in the LM mass spectrum of p-xylylenebis(triphenylphosphonium chloride) (27) (Figure 7). No peak corresponding to the intact dication $(m / z 314)$ is observed. Characteristic ions in the high mass region correspond to the $[\mathrm{C}-1]^{+}$ion at $m / z 627$ and the $[C-2]^{+\cdot}$ ion at $m / z 626$. The $[C-$ $1]^{+}$ion probably results from gas-phase expulsion of $\mathrm{HCl}$ from the $\left[\mathrm{M}-\mathrm{Cl}^{+}\right.$ion $(m / z$ 663), which itself is only detected with negligible signal intensity $(<1 \%$ RA). Generation of $[\mathrm{C}-1]^{+}$ions has been previously reported for LMMS of diquaternary ammonium salts [8] and FDMS of bisphosphonium salts [9, 10]. Subsequent loss of triphenylphosphine from the $[\mathrm{C}-1]^{+}$ ion yields the $\left[\mathrm{Ph}_{3} \mathrm{PCH}\left(\mathrm{C}_{6} \mathrm{H}_{4}\right) \mathrm{CH}_{2}\right]^{+}$fragment ion $(m / z$ 365), which is the base peak in the spectrum (Scheme IV). Expulsion of the $\mathrm{Ph}_{3} \mathrm{PCH}\left(\mathrm{C}_{6} \mathrm{H}_{4}\right) \mathrm{CH}_{2}$
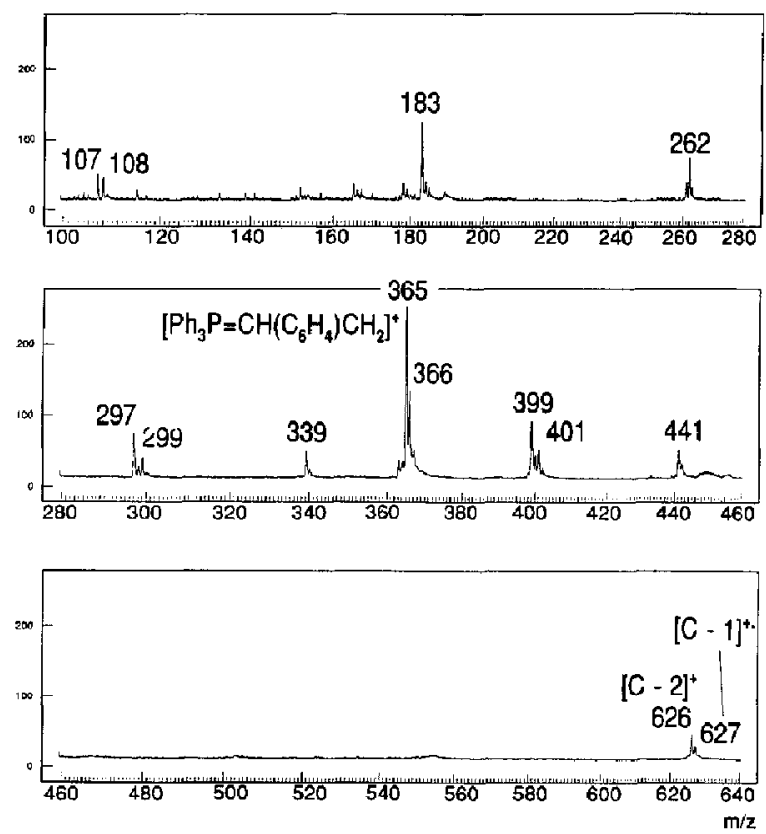

Figure 7. Positive ion LM mass spectrum of p-xylylenebis(triphenylphosphonium chloride) (27). The peak intensities are given in arbitrary units. 


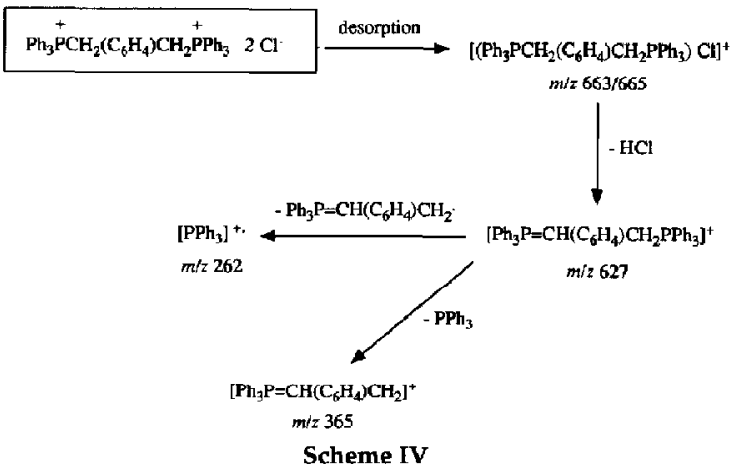

radical leads to the $\left[\mathrm{Ph}_{3} \mathrm{P}\right]^{+-}$ion $(m / z 262)$ and its characteristic fragments at $m / z 261,183,108$, and 107 .

The $[\mathrm{C}-2]^{+\cdot}$ ions at $m / z 626$ are explained by electron ionization of the $[\mathrm{M}-2 \mathrm{HCl}]$ thermal degradation product (Scheme Va). Subsequent expulsion of a $\mathrm{Ph}_{2} \mathrm{P}^{\prime}$ radical via a rearrangement reaction yields the fragment ion at $m / z$ 441. The same fragmentation was observed for FABMS [1]. A second thermal degradation reaction, which involves substitution of a chloride anion into the dication with simultaneous elimination of $\mathrm{PPh}_{3}$ and $\mathrm{HCl}$, yields the mono-ylid shown in Scheme $\mathrm{Vb}$. Electron ionization of this mono-ylid followed by loss of a hydrogen radical or a chloride radical yields the fragment ions at $\mathrm{m} / \mathrm{z} 399 / 401$ (3:1) and $m / z$ 365, respectively. Substitution of halide anions into dications was previously reported for LM [9], solid-SI [11], and FD [5] spectra of diquaternary am-
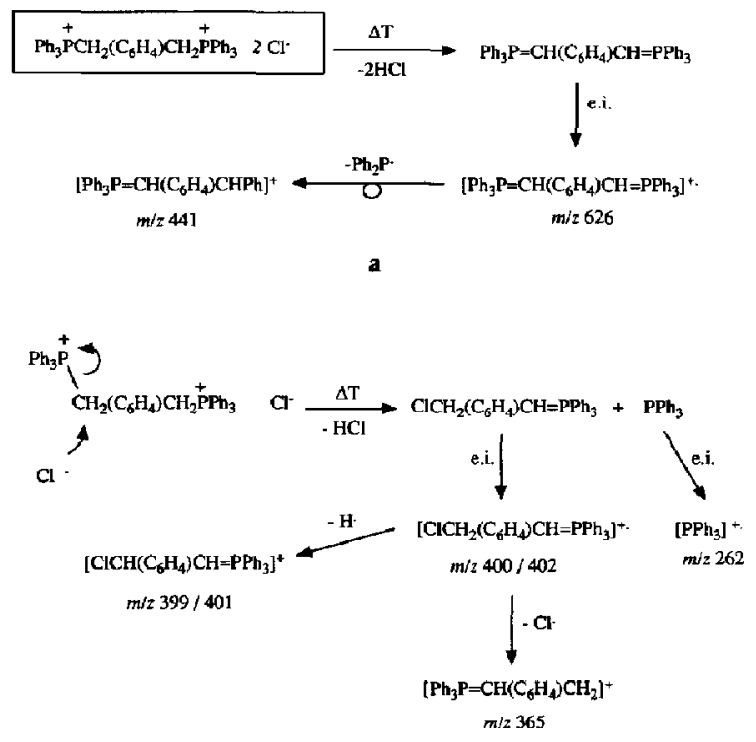

( $\Delta \mathbf{T}=$ thermal degradation ) monium salts. These processes are indicative of the pyrolytic chemistry that occurs in the condensed phase prior to desorption. Other ions in the LM mass spectrum that result from surface recombination reactions are the $\left[\mathrm{Ph}_{3} \mathrm{PCl}\right]^{+}(m / z 297 / 299)$ and $\left[\mathrm{Ph}_{4} \mathrm{P}\right]^{+}(m / z$ 339) ions.

The LM mass spectrum of p-xylylenebis(triphenylphosphonium chloride) (Figure 7) is representative for the LM mass spectra of the other bisphosphonium salts (28-29, 37-40). Additional fragment ions are only observed for 1,4-bis(triphenylphosphoniomethyl)-2,5dimethoxybenzene dichloride (29) (i.e., a [(C - 2) $\left.\mathrm{CH}_{3}\right]^{+}$ion); and for 2,5-bis(triphenylphosphoniomethyl)furan dichloride (37) and 2,5-bis(triphenylphosphoniomethyl)thiophene dichloride (38) (i.e., the $\left[(\mathrm{C}-2)-\mathrm{H}^{+}\right]^{+}$and $\left[(\mathrm{C}-2)-\mathrm{Ph}^{+}\right]^{+}$ions $)$. A comparison of the LMMS and FABMS results for the bisphosphonium salts investigated shows that $[\mathrm{C}-1]^{+}$ and $[\mathrm{C}-2]^{+\cdot}$ ions, together with their characteristic fragment ions, are observed with both techniques. However, results obtained with both DI techniques are not identical. For instance, the FAB mass spectra usually show the intact monocation $\left(\mathrm{C}^{+}\right)$and the doubly charged molecular cation $\left(\mathrm{C}^{2+}\right)$. Neither of these species is detected in the LM mass spectra for any compound. Instead, fewer structure-specific ions that originate from deleterious thermal processes are detected, even at threshold laser irradiance.

\section{Improved Analysis of Phosphonium Salts by "Matrix-Assisted" LMMS}

The results discussed in the previous section show that the positive ion LM mass spectra of the "neat" organic salts (i.e., no matrix) share some typical features with spectra obtained by DI methods (i.e., FABMS and FDMS). The intact cation and its fragment ions $\left[\mathrm{PPh}_{3}\right]^{+\cdot}$ and $\left[\mathrm{C}-\mathrm{PPh}_{3}\right]^{+}$are usually observed for the monophosphonium salts, while for the bisphosphonium salts the $[\mathrm{C}-1]^{+}$and $\left[(\mathrm{C}-1)-\mathrm{PPh}_{3}\right]^{+}$ion species are typically detected. However, the energetic desorption process upon which LMMS of organic solids is based is nearly always accompanied by undesirable side reactions that complicate or preclude successful analysis. In particular, thermal decomposition of the organic salts and deleterious surface recombination reactions are induced, giving rise to detection of less structure-specific ions at the cost of diagnostic ions such as the intact cation. Low laser power densities (threshold) minimize these thermal damage effects, but for particularly refractory samples they still persist and may obscure the relationship between the molecular structure of the salt and its LM mass spectrum (compare 4-(4'-methylstyryl)benzyltriphenylphosphonium chloride) (Figure 3c).

Another drawback of direct LMMS analysis of neat organic solids is the rather poor shot-to-shot spectral reproducibility. Even under standard experimental 
conditions, relative abundances of the major ions can vary by as much as $30-50 \%$ (average of 10 spectra). 'Ihis is caused by the extreme dependence of the spectrum on laser power density (more specifically, the energy absorbed directly by sample molecules) and inhomogeneous sample micromorphology, which strongly influence spectral results both qualitatively (degree of fragmentation) and quantitatively (peak intensities).

The higher degree of thermal damage and the lower spectral reproducibility observed in LMMS as compared to FABMS is likely due to the lack of a matrix. Therefore, it was logical to test the effect of a matrix (liquid or solid) for LMMS as well. Physical isolation of sample molecules is expected to decrease the extent of intermolecular reaction, while the matrix can absorb energy and thus reduce thermal degradation. In this context, recent work by Karas et al. [12] on matrixassisted UV laser desorption of nonvolatile biomolecules deserves attention. Matrix-assisted LMMS refers to the use of selected matrix compounds that strongly absorb at the laser wavelength used to increase ion yields from analytes with unfavorable desorption characteristics. Mixing of an analyte with a large excess of a UV-absorbing matrix facilitates absorption and dissipation of the highly energetic laser irradiation, thereby reducing fragmentation of the analyte and minimizing the contribution of irradiation damage. Impressive results show that high molecular mass biopolymers can be reproducibly desorbed and ionized without serious degradation, enabling molecular mass determination of proteins with molecular masses up to 300,000 dalton [13-16].

In this part we will demonstrate (1) that matrixassisted LMMS also significantly improves the analysis of low molecular mass organic salts and (2) that aryltriphenylphosphonium salts can be effectively used as "molecular thermometers" to probe both the temperatures experienced by the guest molecules embedded in the matrix and the internal energies of the ion species desorbed by matrix-assisted laser desorption. Matrixassisted LMMS experiments were performed on triphenylphosphonium salts $1,6,12,15$, and 27 using four different matrices [i.e., nicotinic acid (NicAc), ammonium chloride $\left(\mathrm{NH}_{4} \mathrm{Cl}\right), 3$-nitrobenzylalcohol (3NBA), and glycerol (Gly)].

The beneficial effects of a solid matrix such as NicAc (a strong UV-absorber at $\lambda=266 \mathrm{~nm}$ ) on the LM mass spectrum of 1-naphthylmethyltriphenylphosphonium chloride (12) are demonstrated in Figure 8 . The three major ionization pathways observed for the neat organic salt are illustrated in Scheme VI. Comparison of the matrix-assisted spectrum (Figure $8 \mathrm{~b}$ ) with the spectrum of the neat salt (Figure 8a) shows an increase of the intact cation [C] ${ }^{+}(\mathrm{m} / z$ 403) ion abundance. The absolute intensity of the signal at $m / z 403$ is approximately three times greater in the spectrum of the matrix-diluted sample (Figure $8 \mathrm{~b}$ ), even though the phosphonium salt is reduced in
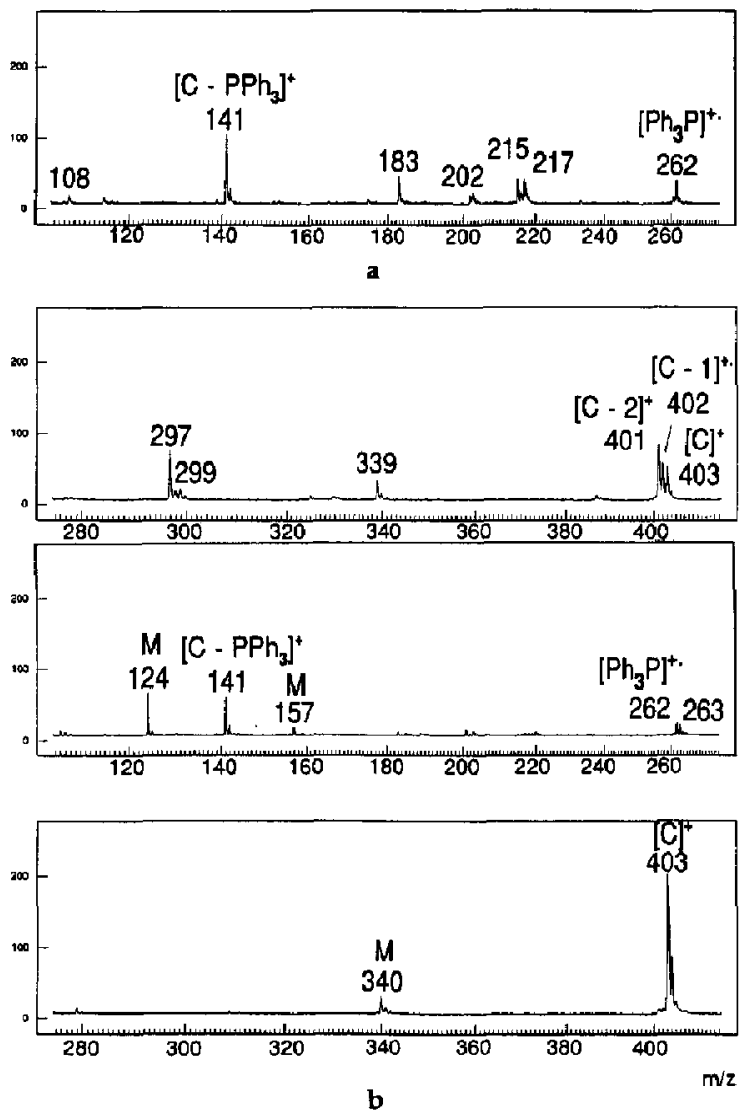

Figure 8. Positive ion LM mass spectra of 1-naphthylmethyltriphenylphosphonium chloride (12): (a) neat sample and (b) diluted in NicAc matrix (1:100); $\mathbf{M}=$ matrix-related ions. The peak intensities are given in arbitrary units.

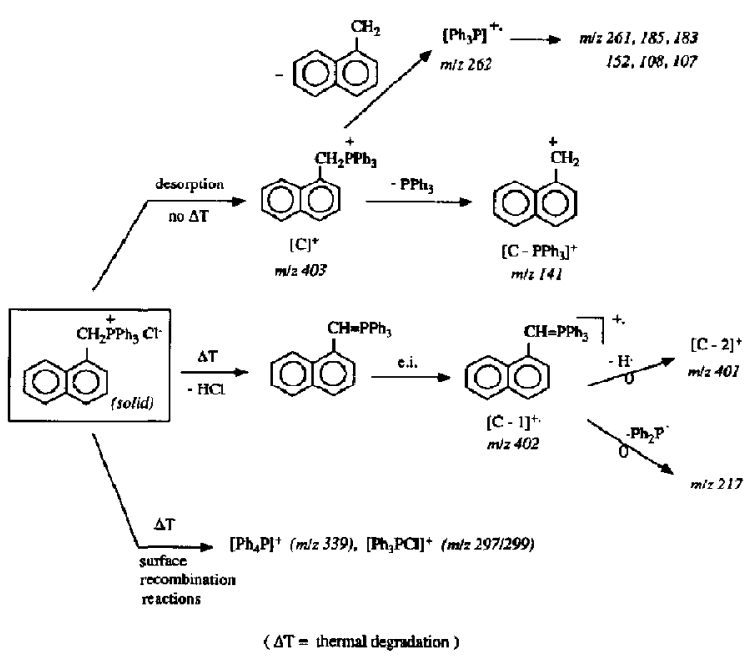

Scheme VI 
amount by a factor of 100 . The total sample loading in this case was $44 \mathrm{ng}$. The lower relative abundance of the characteristic fragment ions at $m / z 141$ and $m / z$ 262 in the matrix-assisted spectrum (Figure $8 \mathrm{~b}$ ) results from the lower internal energy of the intact cations that are desorbed from the NicAc matrix and clearly demonstrate enhancement of "soft" ionization by the UV-absorbing solid matrix. The most remarkable feature of the matrix-assisted spectrum, however, is the complete absence of ions that originate from thermal degradation, such as $[C-1]^{+\cdot}\left(m, z\right.$ 402) and $[C-2]^{+}$ $(m / z 401)$, and from surface recombination reactions, such as $\left[\mathrm{Ph}_{3} \mathrm{PCl}\right]^{+}(m / z 297 / 299)$ and $\left[\mathrm{Ph}_{4} \mathrm{P}\right]^{+}(m / z$ 339). Both features, the higher ion yield of the preformed cation and the improved spectral quality, obviously facilitate interpretation of the LM mass spectrum which contains only a few matrix peaks (labelled with M). Also the shot-to-shot spectral reproducibility is remarkably improved. Whereas for the pure substance spectra, relative ion abundances can vary by as much as $50 \%$, molecular ion abundances in the matrixassisted spectrum vary from shot to shot within $\pm 15 \%$ (average of 10 shots). This is approximately the variation of the laser energy from shot to shot, provided the focusing of the laser is not changed between the shots.

The applicability of the liquid matrices glycerol and 3-NBA were also tested. These two compounds are the most widely used matrices in FABMS $[17,18]$. Only 3-NBA contains an aromatic group that shows resonant absorption at $266 \mathrm{~nm}$. The LM mass spectra of 1-naphthylmethyltriphenylphosphonium chloride (12) in glycerol and 3-NBA are shown in Figure 9. In contrast to the corresponding FAB mass spectra, no glycerol or 3-NBA cluster ions are observed. The lack of these matrix ions suggest that the ionization process occurs under relatively high temperature conditions.

Comparison with the LM mass spectrum of the neat salt (Figure 8a) indicates that addition of a liquid matrix significantly increases the abundance of the intact cation $(m / z 403)$ while reducing the degree of fragmentation and thermal degradation. However, in contrast to the matrix-assisted spectrum obtained in NicAc (Figure 8b), we can still observe some ions resulting from thermal degradation (i.e., at $m / z 402$ and $m / z$ 401) and surface recombination reactions (i.e., at $m / z 339$ and $m / z 297 / 299$ ). The higher relative abundances of the $\left[\mathrm{C}-\mathrm{PPh}_{3}\right]^{+}(m / z$ 141) and $\left[\mathrm{PPh}_{3}\right]^{+}$fragment ions also point to increased fragmentation of intact cations that are desorbed from the liquid matrix. Both features mentioned above point to a lower cooling effect of the liquid matrices compared with that of the solid UV-absorbing NicAc matrix.

Based on the results obtained for 1-naphthylmethyltriphenylphosphonium chloride (12), we propose a method for estimating the cooling effect of various matrices for LMMS using aryltriphenylphosphonium salts as molecular thermometers. This method is based on calculations of two parameters (namely, $\sigma_{\mathrm{TL}}$ and $\sigma_{\mathrm{IE}}$ ), which quantitatively reflect the thermal
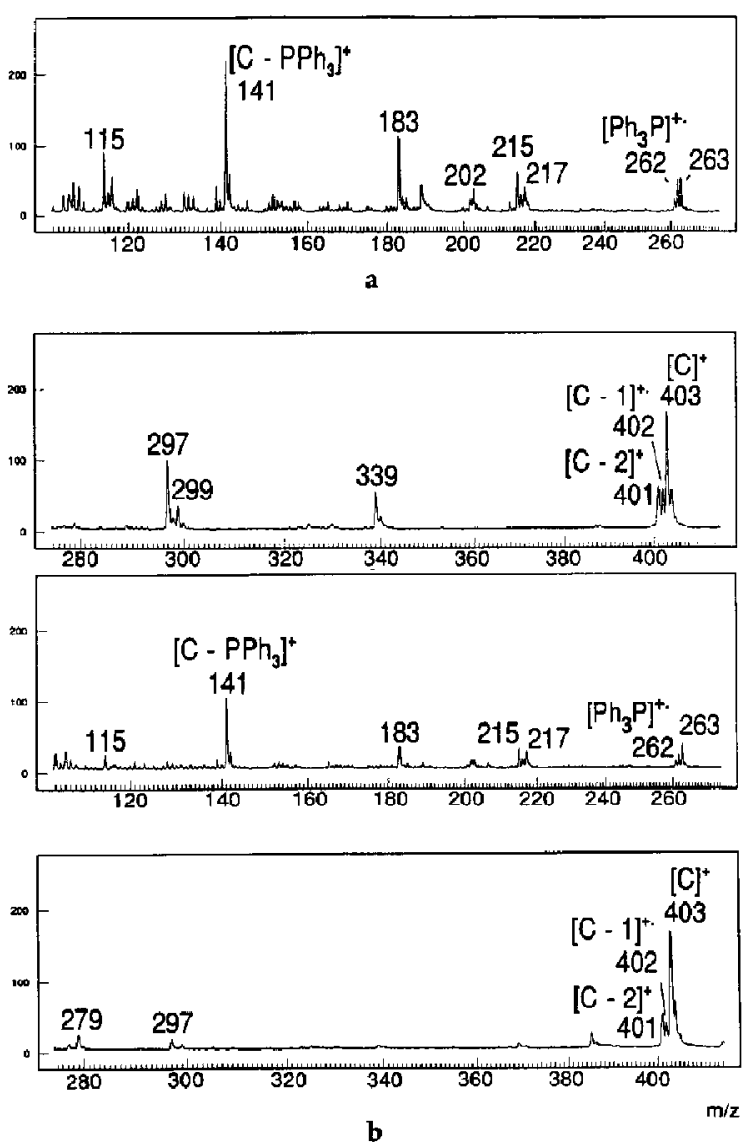

Figure 9. Matrix-assisted LM mass spectra of 1-naphthylmethyltriphenylphosphonium chloride (12) diluted in (a) glycerol and (b) 3-nitrobenzylalcohol (1:100). The peak intensities are given in arbitrary units.

load (TL) on the salt and the internal energy (IE) content of the desorbed cations. $\sigma_{\mathrm{TL}}$ corresponds to the intensity ratio of the thermal degradation ions $\left([\mathrm{C}-1]^{+\cdot}\right.$ and $\left.[\mathrm{C}-2]^{+}\right)$versus the intact cation $\left([\mathrm{C}]^{+}\right)$, which can be considered to be a direct measure of the thermal load on the phosphonium salt during the laser desorption process (eq 3 ).

$$
\sigma_{\mathrm{TL}}=\frac{\mathrm{I}_{[\mathrm{C}-1]^{+}}+\mathrm{I}_{[\mathrm{C}-2]^{+}}}{\mathrm{I}_{[\mathrm{C}]^{+}}}
$$

$\sigma_{\mathrm{IE}}$ corresponds to the intensity ratio of the [C $\left.\mathrm{PPh}_{3}\right]^{+}$fragment ion versus the intact cation $\left([\mathrm{C}]^{+}\right)$, which can be regarded to be directly related with the internal energy of the desorbed intact cations (eq 4).

$$
\sigma_{\mathrm{IE}}=\frac{\mathrm{I}_{\left[\mathrm{C}-\mathrm{PPh}_{3}\right]^{+}}}{\mathrm{I}_{[\mathrm{C}]^{+}}}
$$

Similar ion current ratios were used to monitor inter- 
nal energies during FAB and laser desorption processes [19]. The use of ion current ratios to monitor the thermal load (i.e., the degree of thermal degradation) is an original contribution of this study that provides additional information for characterizing the physical processes occurring during laser desorption. In general, the lower the values of $\sigma_{\mathrm{TL}}$ and $\sigma_{I \mathrm{E}}$ for a given matrix, the greater will be its cooling effect. A comparison of the $\sigma_{\mathrm{TL}}$ and $\sigma_{\mathrm{IE}}$ values calculated for 1naphthylmethyltriphenylphosphonium chloride (12) analyzed in neat form, NicAc, glycerol and 3-NBA (Figure 10) shows that the cooling effect of these matrices increases in the order glycerol $<3-\mathrm{NBA}<\mathrm{NicAc}$. Differences in the $\sigma_{\mathrm{TL}}$ and $\sigma_{\mathrm{IE}}$ values can be correlated with physical properties of the various matrices. Two important physical properties that determine the effectiveness of a matrix to minimize thermal degradation reactions and to reduce the internal energy of the desorbed ions are the UV-absorption characteristics and the volatilization temperature of the matrix material. Matrices with a high cooling effect usually exhibit
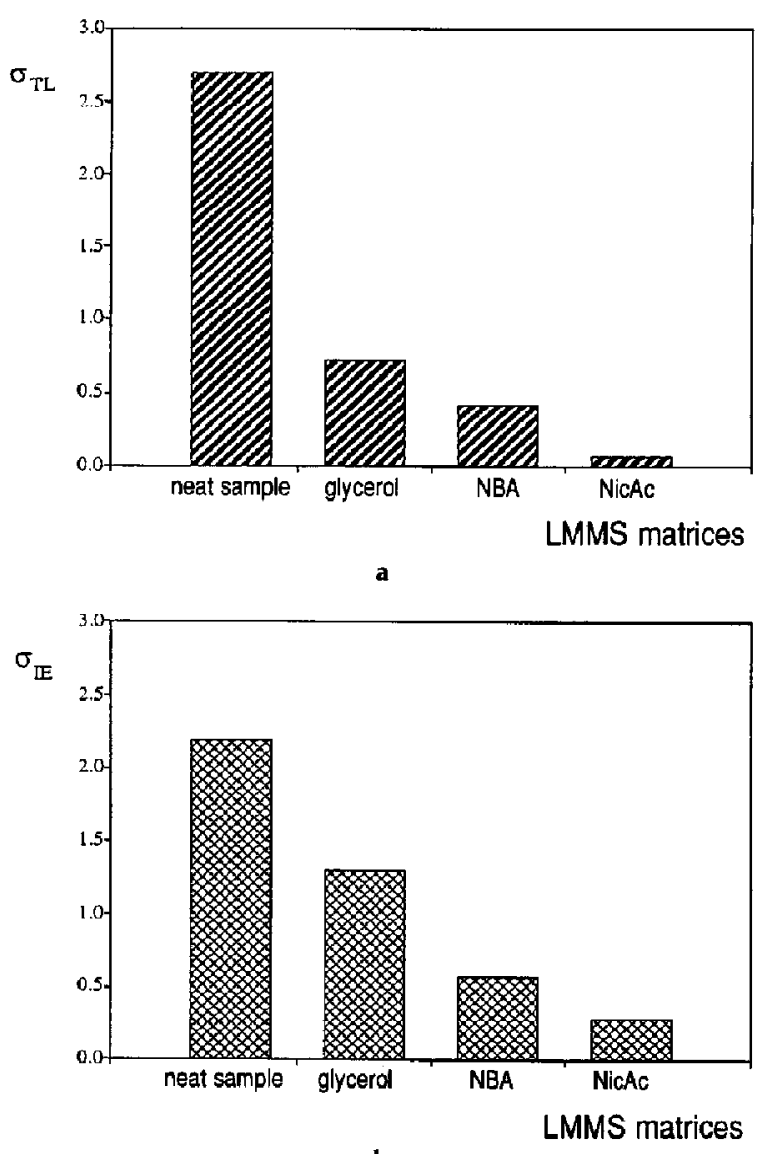

b

Figure 10. (a) $\sigma_{\mathrm{TL}}$ and (b) $\sigma_{\mathrm{IE}}$ values obtained for 1-naphthylmethyltriphenylphosphonium chloride (12) analyzed in neat form, glycerol, 3-NBA, and NicAc. strong resonant absorption at the wavelength of the incident laser light $(\lambda=266 \mathrm{~nm})$ and have a low boiling/sublimation point (e.g., NicAc and 3-NBA). Lower cooling effects are observed for matrices that do not absorb strongly at $266 \mathrm{~nm}$ (e.g., glycerol and $\mathrm{NH}_{4} \mathrm{Cl}$ : see below).

A comparison of the LM mass spectra of benzyltriphenylphosphonium chloride (1) analyzed in the solid matrices NicAc (Figure 11a) and $\mathrm{NH}_{4} \mathrm{Cl}$ (Figure 11b) also demonstrates that strong UV-absorption of the matrix molecules at the laser wavelength used, is a prerequisite for controlled energy deposition and soft desorption of the organic salts. Despite the fact that both solid matrices have low sublimation temperatures, only the spectrum obtained in the strongly UVabsorbing NicAc matrix is free from ions that result from thermal degradation and surface recombination reactions (Figure 11a). This is not the case for the spectrum obtained in the non-UV-absorbing $\mathrm{NH}_{4} \mathrm{Cl}$ matrix (Figure 11b) which resembles the LM mass
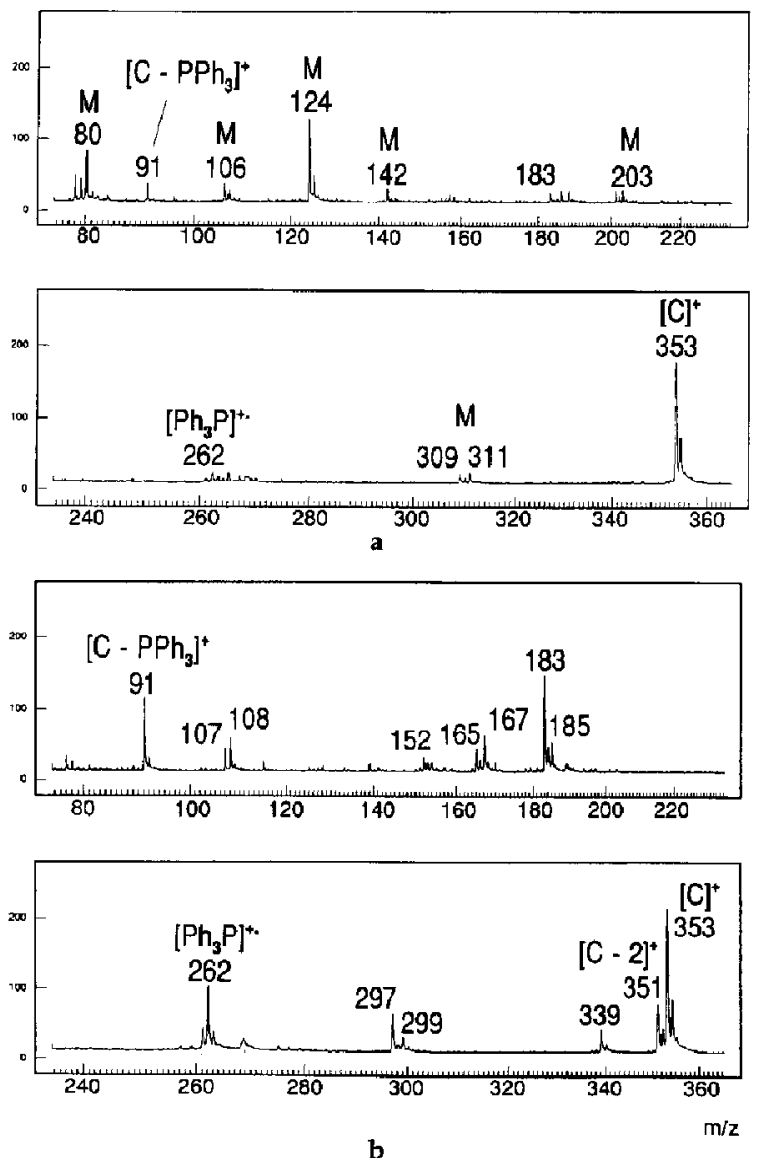

Figure 11. Matrix-assisted LM mass spectra of benzyltriphenylphosphonium chloride (1) diluted in (a) NicAc and (b) $\mathrm{NH}_{4} \mathrm{Cl}(1: 100) ; \mathrm{M}-$ matrix-related ions. The peak intensities are given in arbitrary units. 
spectrum of the neat salt (Figure 1). The only difference is the higher signal intensity for the intact cation $(m / z 353)$.

The $\sigma_{\mathrm{TL}}$ and $\sigma_{\mathrm{IE}}$ values calculated for benzyltriphenylphosphonium chloride analyzed in neat form, NicAc, $\mathrm{NH}_{4} \mathrm{Cl}, 3-\mathrm{NBA}$ and glycerol (Figure 12) also point to the high cooling effect of the NicAc and 3-NBA matrices, compared to the non-UV-absorbing matrices glycerol and $\mathrm{NH}_{4} \mathrm{Cl}$ which both show approximately the same cooling effect.

We also found it of interest to compare the matrixassisted LM mass spectra of benzyltriphenylphosphonium chloride (Figure 11a) with the corresponding FAB mass spectrum [1]. The higher relative abundance of the $\left[\mathrm{C}-\mathrm{PPh}_{3}\right]^{+}$fragment ion $(\mathrm{m} / z$ 91) and the detection of thermal degradation ions (i.e., $[C-1]^{+\cdot}$ at $m / z 352$ and $[C-2]^{+}$at $\left.m / z 351\right)$ in the FAB mass spectrum, indicate that matrix-assisted LMMS (with NicAc) is a "softer" ionization technique than FABMS.

The extreme impact of the choice of the matrix on the appearance of the matrix-assisted LM mass spectra arises from interacting effects of UV-absorption, solva-
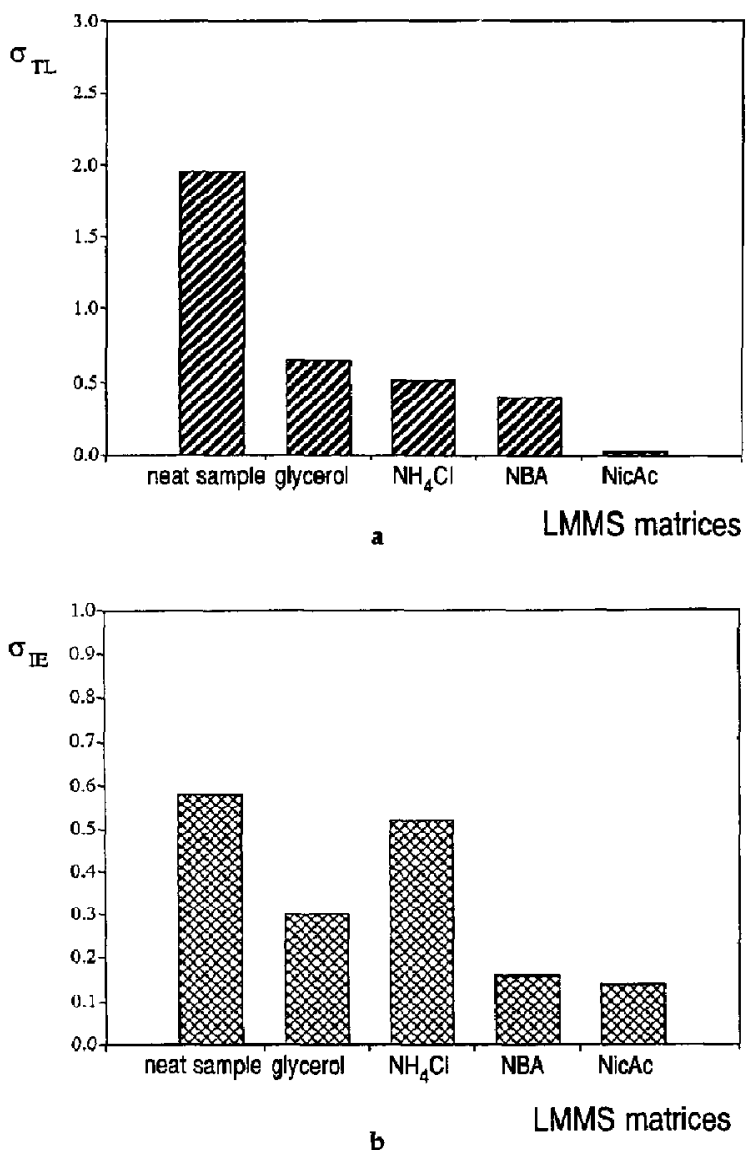

Figure 12. (a) $\sigma_{\mathrm{TL}}$ and (b) $\sigma_{\mathrm{IE}}$ values obtained for benzyltriphenylphosphonium chloride (1) analyzed in neat form, glycerol, $\mathrm{NH}_{4} \mathrm{Cl}, 3-\mathrm{NBA}$, and NicAc. tion, solution chemistry and volatilization. In the case of the liquid matrices (glycerol, 3-NBA), additional surface eftects dependent on their polarity cannot be excluded. Separation of all these closely related effects is generally not feasible. However, the fact that quaternary aryltriphenylphosphonium salts can be used as "molecular thermometers" in LMMS to probe both the thermal load on the sample molecules during the laser desorption process and the internal energies of the desorbed ion species, demonstrates that they are suitable target compounds for testing whether improvements have been achieved by adopting different sample treatments. In conjunction with compilations of matrix physical properties [14], consideration of $\sigma_{\mathrm{TT}}$. and $\sigma_{\mathrm{IE}}$ values should facilitate matrix optimization in LMMS. Until now, the best results for the phosphonium salts are obtained with the solid, UV-absorbing NicAc matrix. NicAc was, therefore, selected as the matrix of choice for the remaining experiments discussed in this study.

Two other examples, illustrating that UV-matrixassisted LMMS is useful for improved structural characterization of phosphonium salts, are given below. Figure 13 shows the molecular ion region of the matrixassisted LM mass spectrum of 4-(4'-methyl-styryl) henzyltriphenylphosphonium chloride (6), analyzed in NicAc. In contrast to the LM mass spectrum of the neat salt (Figure 3c), which only gives a negligible intact cation signal intensity, the matrix-assisted ionization process dramatically improved the abundance of the intact cation at $m / z 469$ (Figure 13). The relative abundances of the $[\mathrm{C}-1]^{+}$and $[\mathrm{C}-2]^{+}$thermal degradation ions are less than $5 \%$.

Figure 14 shows the matrix-assisted LM mass spectrum of $n$-dodecyltriphenylphosphonium bromide (15). Even though $\mathrm{C}^{+}$ions $(\mathrm{m} / \mathrm{z} 431)$ could be produced by laser desorption of the neat salt (Figure 5), addition of NicAc significantly increases the abundance of the preformed cation while reducing the degree of fragmentation observed (Figure 14). Another indication of the lower internal energy of the plosphonium cations that are desorbed from the NicAc matrix, is the higher $m / z 263: m / z 262$ fragment ion abundance ratio. According to a study on the mass spectral behavior of alkyltriphenylphosphonium salts by McCrery et al. [19], the abundance ratio of the fragment ions at $\mathrm{m} / \mathrm{z}$ 263 and $m / z 262$ (which originate from a rearrangement process and simple cleavage of the intact cation, respectively) can be regarded as an indicator of the internal energy distribution of the fragmenting phosphonium cations.

Also for the bisphosphonium salts (27-40), addition of the NicAc matrix yields simply interpretable LM mass spectra which are free from ions that result from thermal degradation and surface recombination reactions. Another matrix-enhancement effect observed for the bisphosphonium salts is an increase of the relative abundance of the $[\mathrm{C}-1]^{+}$or $[\mathrm{M}-\mathrm{A}-\mathrm{HA}]^{+}$ion (with $\mathrm{M}=$ salt molecule and $\mathrm{A}=$ anion). However, 


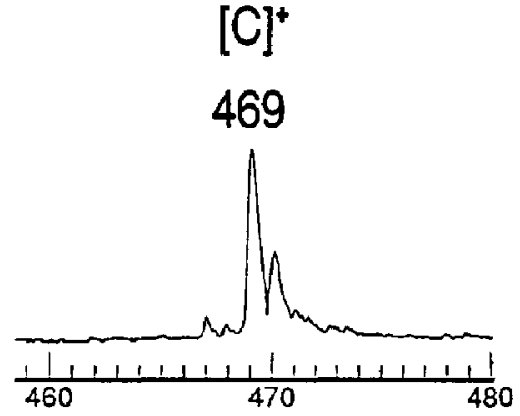

Figure 13. Matrix-assisted LM mass spectrum (intact cation $m / z$ region) of 4 (4'-methylstyryl)-benzyltriphenylphosphorium chluride (6) diluled in NicAc (1:100).

presence of the UV-absorbing matrix did not lead to detection of free dications, $\mathrm{C}^{2+}$. Failure to detect dications is probably due to the high energy requirement for direct desorption of these multiply charged ions, which makes lower energy desorption pathways favored.

An interesting analytical aspect of matrix-assisted LMMS for the analysis of phosphonium salts is the remarkably high sensitivity. Full mass spectra, which contain only a few matrix-related peaks, can easily be obtained from a total sample amount in the subnanogram range. Optimal absolute sample amounts are in the low picomole to high femtomole range. However, the sensitivity can be further improved to values of tens of femtomoles by using less concentrated solutions as well as smaller volumes of sample and matrix solution (see Experimental). The actual amount of sample really consumed in the recording of a matrix-assisted LM mass spectrum is much less and virtually the whole sample can be recovered after analysis. For example, to obtain the matrix-assisted spectrum of 1-naphtylmethyltriphenylphosphonium
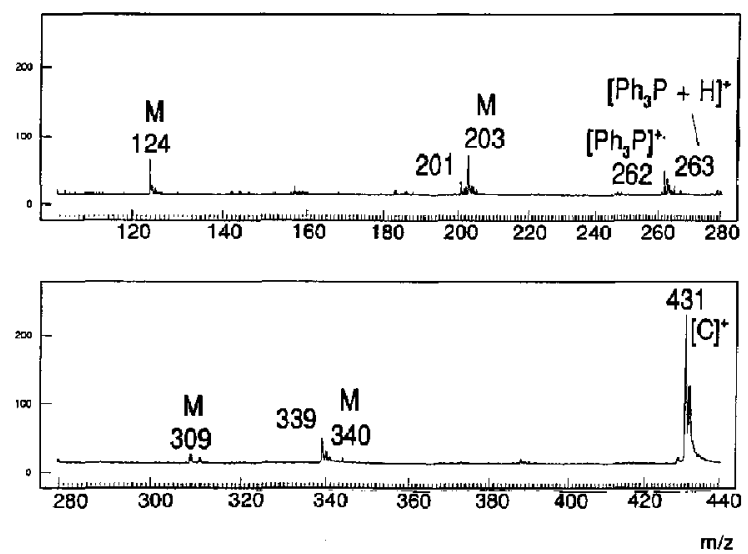

Figure 14. Matrix-assisted LM mass spectrum of n-dodecyltriphenylphosphonium bromide (15) diluted in NicAc (1:100); $\mathbf{M}=$ matrix-related ions. The peak intensities are given in arbitrary units. chloride (Figure $8 \mathrm{~b}$ ) an absolute sample amount of 44 ng was spread over an area of $3 \mathrm{~mm}^{2}$. Only about $3.10^{-5} \mathrm{~mm}^{2}$ of this total sample area was ablated by the fifteen laser shots which result in the sum spectrum shown in Figure 8b. This corresponds to a sample consumption for recording one LM mass spectrum of $0.44 \mathrm{pg}$ (or $1 \mathrm{fmol}$ ).

Analyte ions can be observed over a broad range of sample-matrix dilutions, that is, from $1: 2$ to $1: 10^{6}$. Experiments with salt 12, however, indicate that optimal detection of organic salt ions (i.e., maximum ion yield) takes place at a $10^{2}$ molar excess of $\mathrm{NicAc}$ matrix. At higher sample-matrix ratios $(>1: 10)$ increased fragmentation of the intact cations and appearance of competitive processes, such as thermal decomposition and other deleterious surface reactions, will lead to a drop in the intact cation ion abundance. Lower sample-matrix ratios $\left(<1: 10^{3}\right)$ will ultimately result in a decrease in the absolute number of preformed ions desorbed and to an increase in the contribution of background ions originating from the matrix. This is illustrated in the matrix-assisted LM mass spectrum of salt 12 which is obtained at a dilution of $1: 10^{4}$ in NicAc (Figure 15). The total sample loading in this case was $0.44 \mathrm{ng}$. Both the intact cation at $m / z 403$ and the fragment ion at $m / z 141$ are still observed with good $S / N$ ratio. However, the absolute ion abundance of the $\mathrm{C}^{+}$ion $(m / z \quad 403)$ is lower and the relative contribution of the matrix-related ions is higher than in the spectrum obtained at a dilution of 1:10 ${ }^{2}$ (Figure $8 b)$. The intact cation/fragment ion abundance ratio (i.e., $m / z 403 / m / z 141$ ) is slightly higher for the more diluted sample, indicating that an increasing dilution of the sample leads to a decrease in the degree of fragmentation. For dilutions lower than 1:104, the same intact cation/fragment ion abundance ratio is observed, which means that there is a leveling in the effect of dilution upon fragmentation. A detailed in-
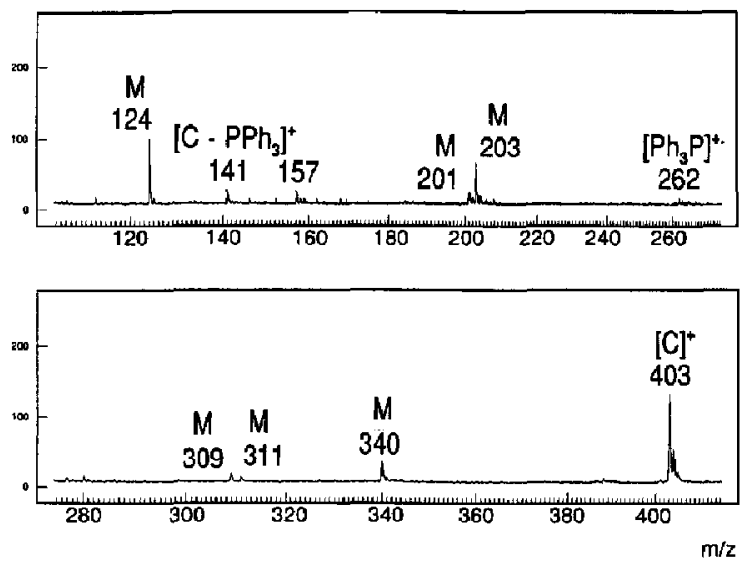

Figure 15. Matrix-assisted LM mass spectrum of 1-naphthylmethyltriphenylphosphonium chloride (12) in NicAc at a $1: 10^{4}$ dilution; $M=$ matrix-related ions. The peak intensities are given in arbitrary units. 
vestigation of the detection limits for the analysis of phosphonium salts, over a wide range of concentrations, was not performed. However, based on the previous results, detection limits in the subpicogram range for the total sample amount appear to be realistic.

An approximate calculation of the ionization yield ratio of the number of desorbed intact cations to the number of salt molecules in the volume analyzed for this matrix-diluted sample gives a value of about $0.01 \%$. This is approximately a factor of $5.10^{4}$ greater than the ionization yield for the neat organic salt. The high ion yield obtained for the matrix-embedded samples suggests that, at least for the phosphonium salts investigated, the transfer of sample from the condensed phase into the gas phase is remarkably efficient.

The results obtained for the aryltriphenylphosphonium salts also provide valuable information on the energy transfer processes leading to volatilization of nonvolatile compounds in matrix-assisted LMMS. Qualitative understanding of the mechanisms of laser ion formation is a necessary precondition to find the optimal analysis conditions and to derive maximum information from LM mass spectra. The hypothesis was that in the case of matrix-assistance, laser energy is primarily deposited in the form of electronic excitation of the matrix. These excited electronic states can decay through fluorescence, photodissociation, or internal conversion. Internal conversion leads to vibrationally highly excited ground states. This vibrational energy can be communicated either to the lattice vibrations (leading to volatilization) or to the embedded salt (leading to fragmentation and thermal degradation). The lack of thermal degradation of the phosphonium salts and clear indications of significantly lower internal energies of preformed cations that are desorbed from the UV-absorbing NicAc matrix (Figure 8b), point to a hindered energy transfer towards the embedded salt molecules (ions). The role of the matrix can be regarded to be threefold:

- By providing a large molar excess of matrix molecules, analyte molecules (ions) are separated from each other, thereby reducing strong intermolecular forces (i.e., matrix isolation). For the phosphonium salts solvation of cations and anions leads to charge separation which lowers the energy required for their desorption and reduces the probability for thermal degradation of the salt.

- The resonantly absorbing matrix enables an effective and controllable coupling of the laser energy into the condensed phase. If the laser wavelength (266 nm) coincides with a resonance absorption band of the matrix, each photon absorbed will create an excited-state matrix molecule. The energy primarily stored by the electronically excited matrix molecules will be quickly converted into vibrational energy. A considerable amount of energy is thereby deposited into the condensed phase. This results in a rapid, explosive disintegration of the condensed phase, which takes place before equilibration of the energy into all degrees of freedom can lead to destruction of the embedded salt molecules (ions). Thus, the process of disintegration has to be understood as a nonequilibrium process [11].

- The third role of the matrix may involve the stabilization of desorbed ion species, induced by expansion cooling in the generated plume of the sublimating matrix (see below).

All these processes are summarized in the bottleneck and cool plume model, proposed by Vertes et al. [20, 21]. According to the "homogeneous bottleneck model" the laser energy is initially deposited through electronic excitation of matrix molecules. This energy is transformed into vibrational energy of the lattice, the matrix molecules and the analyte ions. However, energy transfer to analyte ions is largely prohibited by a mismatch between the vibrational frequency of the ion-dipole interactions connecting the embedded ions to the matrix and the internal vibrational frequencies of the matrix molecules (i.e., there is an energy transfer bottleneck) [20]. Laser heating of the sample leads to phase transition of the matrix when the volatilization (sublimation) temperature is reached. At this stage strong evaporation occurs and the generated plume expands into the vacuum. According to the laws of gas dynamics this expansion leads to a dramatic drop in the plume temperature. This effect brings about stabilization of analyte ions just the way like jet cooling devices are working [21]. The presence of entrainment is supported by velocity distribution measurements on neutral matrix and guest molecules. Huth-Fehre and Becker [22] found almost identical velocity distributions for gramicidin $S$ guest and ferulic acid matrix molecules. The volatilization mechanism of nonvolatile compounds in matrix-assisted LMMS can thus be described by a combination of these two mechanisms, that is, an energy transfer bottleneck in the solid phase and expansion cooling in the gas phase [21].

\section{Conclusions}

The results obtained for the phosphonium salts clearly show that LMMS deserves a distinct place within the range of DI techniques which can cope with polar and ionic compounds that are intractable by conventional techniques. It is demonstrated that matrix-assisted LMMS, which is an extremely valuable technique for the molecular ion generation and molecular mass determination of very large biomolecules [15], can also be effectively used for "improved" analysis of low molecular mass organic salts. The use of a suitable UV-absorbing matrix, such as nicotinic acid, (1) leads to higher signals for preformed cations, (2) minimizes deleterious thermal processes, (3) enables to control 
the internal energy of desorbed cations, and (4) improves the shot-to-shot spectral reproducibility. The high sensitivity of the matrix-assisted technique and the recent introduction of a whole variety of new UV-absorbing matrices $[14,23]$ will certainly extend the application field of LMMS to other classes of organic salts, organic hydrochlorides, and thermolabile compounds. Further improvements in sample preparation and sample handling should follow from a better understanding of the mechanisms of laser ion formation and will lead to more routine utilization of the technique.

Triphenylphosphonium salts with polycyclic aromatic substituents can be used as "molecular thermometers" in LMMS, to probe both the thermal load experienced by sample molecules during the laser DI process and the internal energies of desorbed ion species. Furthermore, these salts can be used as a reference tool by laboratories interested in the knowledge of the amount of heat and internal energy deposited into the target when analyzing nonvolatile organic compounds with other soft ionization techniques. For example, comparison of the matrix-assisted LM mass spectra with the FAB mass spectra of the aryltriphenylphosphonium salts indicates that matrixassisted LMMS is a softer ionization technique than FABMS

\section{References}

1. Claereboudt, J.; Baeten, W.; Geise, H.; Claeys, M. Org. Mass Spectrom. 1993, 28, 71.

2. Bacten, W. Ph.D. thesis, University of Antwerp, 1988.

3. Vertes, A.; Balazs, L.; Gijbels, R. Rapid Commun. Mass Spectrom. 1990, 4, 263.
4. Wood, G. W.; McIntosh, J. M.; Pui-Yan, L. J. Org. Chem. 1975, $40,636$.

5. Heller, D. N.; Yergey, J.; Cotter, R. J. Anal. Chem. 1983, 56, 1310.

6. Williams, D. H.; Findeis, A. F.; Naylor, S.; Gibson, B. W. I. Am. Chen. Soc. 1987, 109, 1980.

7. Heinen, H.; Meier, S.; Vogt, H.; Wechsung, R. Adv. Mass Spectrom. 1980, 8, 942 .

8. Hercules, D. M.; Dy, R. J.; Balasanmugan, K.; Dang, T. A.; Li, C. P. Anal. Chem. 1982, 54, 280A.

9. Dang, T,; Day, R, Hercules, D. Annl. Chem. 1984, 56, 866.

10. Sammons, M. C; Bursey, M. M.; White, C. K. Anal Chem. 1975, $47,1165$.

11. Day, R. J; Unger, S. E.; Cooks, R. G. Anal Chem. 1980, 52, 557A.

12. Karas, M.; Bachmann, D.; Bahr, U.; Hillenkamp, F. Int. I. Mass Spectrom. Ion Processes 1987, 78, 53.

13. Karas, M.; Hillenkamp, F. In: Microbeam Analysis-1989; Russell, P. E., Ed.; San Francisco Press: San Francisco, CA, 1989; p 353.

14. Beavis, R. C.; Chait, B. T. Rapid Commun. Mass Spectrom. 1989, 3, 233.

15. Karas, M.; Bahr, U. Trends in Anal. Chem. 1990, 9, 321.

16. Spengler, B.; Cotter, R. J. Anal. Chem. 1990, 62, 793.

17. Gower, J. Biomed. Mass Spectrom. 1985, 12, 191.

18. Sweetman, B.; Blair, I. Biomed. Environ. Mass Spectrom. 1988, $17,337$.

19. McCrery, D.; Peake, D.; Gross, M. Anal. Chem. 1985, 57, 1181.

20. Vertes, A.; Gijbels, R.; Levine, R. D. Rapid Cornmun. Mass Spectrom. 1990, 4, 228.

21. Vertes, A.; Gijbels, R. In: Laser Ionization Mass A nalysls; Vertes, A.; Gijbels, R.; Adams, F., Eds.; Wiley: New York, 1993; p 127.

22. Huth-Fehre, T.; Becker, C.H. Rapid Commun. Masis Spectrom. 1991, 5, 378.

23. Beavis, R.C.; Chait, B. T. Rapid Commun. Mass Spectrom. 1989, 3. 432 . 